\title{
Implantação, planejamento e monitoramento do Núcleo de Apoio à Saúde da Família: um estudo nacional a partir do PMAQ-AB
}

\author{
Alline Lam Orué ${ }^{1}$ \\ Mestre pela Universidade Federal de Mato Grosso do \\ Sul, Campo Grande, Mato Grosso do Sul, Brasil \\ allinelam@yahoo.com.br \\ Albert Schiaveto de Souza \\ Professor Doutor da Universidade Federal de Mato Grosso \\ do Sul, Campo Grande, Mato Grosso do Sul, Brasil \\ albertss@hotmail.com \\ Alcindo Antônio Ferla \\ Professor Doutor da Universidade Federal do Rio Grande \\ do Sul, Porto Alegre, Rio Grande do Sul, Brasil \\ ferlaalcindo@gmail.com \\ Débora Dupas Gonçalves do Nascimento \\ Pesquisadora Doutora da Fiocruz Mato Grosso do Sul, \\ Campo Grande, Mato Grosso do Sul, Brasil \\ debora.dupas@fiocruz.br \\ Mara Lisiane de Moraes dos Santos \\ Professora Doutora da Universidade Federal de Mato Grosso \\ do Sul, Campo Grande, Mato Grosso do Sul, Brasil \\ maralisi@globo.com
}

Resumo $\mathrm{O}$ estudo analisa a implantação, o planejamento e

1 Colaboradores: Alline Lam Orué contribuiu substancialmente para a concepção, planejamento e desenvolvimento do estudo, na interpretação dos dados e na redação do artigo, Albert Schiaveto de Souza contribuiu substancialmente para a análise estatística e apresentação dos dados, Alcindo Antônio Ferla contribuiu substancialmente para a revisão crítica do conteúdo, Débora Dupas Gonçalves do Nascimento contribuiu substancialmente para a revisão crítica do conteúdo, Mara Lisiane de Moraes dos Santos contribuiu substancialmente para a concepção e revisão crítica do conteúdo. 
monitoramento do Núcleo de Apoio à Saúde da Família (NASF). Fundamenta-se nos dados da avaliação externa do segundo ciclo do PMAQ-AB, agrupados segundo a classificação dos perfis de município proposta pelo IBGE, sendo a amostra composta por 18.930 equipes de saúde. A composição das equipes de apoio apresentou-se insatisfatória para a $\mathrm{AB}$, contudo o planejamento conjunto das ações mostrou-se frequente, principalmente em regiões metropolitanas. A maioria das equipes revelou avaliar-se apenas através da autoavaliação do programa. O NASF foi implantado sem a devida articulação com a AB, centralizado na gestão, principalmente nas capitais, onde, entretanto, planejou suas ações de forma mais sistemática. Tal planejamento mostrouse organizado, periódico e articulado, porém com mecanismos compensatórios por parte dos NASF nos perfis caracterizados pela vulnerabilidade socioeconômica. O monitoramento ainda é uma atividade subexplorada em todo o país, exceto quando induzidas pelo incentivo financeiro proporcional à nota das equipes participantes do programa.

Palavras-chave: Atenção primária à saúde, estratégia saúde da família, equipe de assistência ao paciente, avaliação de desempenho profissional, remuneração.

\section{Introdução}

O trabalho das equipes de Atenção Básica $(\mathrm{AB})$, já amplamente disseminado no país, pode ser complementado pelo apoio de equipe denominada de Núcleo de Apoio à Saúde da Família (NASF), visando à integralidade do cuidado. O sucesso desta parceria depende do compartilhamento da responsabilidade no desenvolvimento das ações de saúde (Barros, 2015).

Como o NASF consiste em um modelo de atenção à saúde cuja organização e processo de trabalho são inovadores, com três alternativas de modalidade de equipe - NASF 1 para apoiar 5 a 9 equipes de AB, NASF 2 para 3 a 4 equipes e NASF 3 para até 2 equipes implantada(s) de acordo com a necessidade de cada município (Brasil, 2014a; Lancman et al., 2013), admite-se que existam variações na atuação das equipes, conforme diferentes aspectos, como a região brasileira, o território de atuação, as equipes que compõem a $\mathrm{AB}$ e o NASF, a política municipal, entre outros. Considerando as peculiaridades da proposta NASF, processos avaliativos acerca do mesmo são extremamente relevantes (Nascimento, 2014). Nessa perspectiva o Programa Nacional de Melhoria do Acesso e da Qualidade da Atenção Básica (PMAQ-AB) inseriu um módulo específico para avaliar os NASF do país (Brasil, 2013).

O PMAQ-AB é um processo avaliativo realizado em etapas, de modo sistemático e periódico, que caminha no sentido de ajudar a enfrentar os desafios existentes na base da saúde pública brasileira, com vistas ao acesso, à qualidade e ao fortalecimento das ações da AB (Mota; David, 2015). Por meio dele buscou-se um diagnóstico da situação e resolubilidade das equipes de $\mathrm{AB}$ atuantes no país, o que possibilita a reflexão sobre suas potencialidades e fragilidades, e, por conseguinte, a tomada de decisões com base em evidências (Melo et al., 2016).

A terceira destas etapas é a avaliação externa, a partir da qual ocorreu, in loco, a coleta de informações acerca das equipes participantes do PMAQ-AB. No segundo 
ciclo do PMAQ-AB foram inseridas informações sobre as equipes NASF e sobre o processo de trabalho desenvolvido pelas mesmas (Brasil, 2013). Até então o levantamento de informações e pesquisas sobre o NASF no país foram desenvolvidos: a) a partir do primeiro ciclo do PMAQ-AB, do qual o NASF não participou ativamente, constituindo apenas um dos temas questionado a outras equipes (Lima, 2016); b) pontualmente em municípios e regiões específicas e/ou; c) contemplando o processo de trabalho de categorias profissionais singulares.

Por meio do segundo ciclo do PMAQ-AB, pela primeira vez, um grande número de equipes NASF foi submetida a um processo de avaliação específico, vasto e padronizado, de abrangência nacional. Assim, o objetivo do estudo foi analisar os resultados da avaliação externa do Programa Nacional de Melhoria do Acesso e da Qualidade da Atenção Básica para o Núcleo de Apoio à Saúde da Família, a respeito do processo de implantação das equipes e do planejamento e monitoramento de suas ações, de acordo com o perfil demográfico dos municípios.

\section{Metodologia}

Trata-se de uma pesquisa analítica, seccional, de abordagem quantitativa, com base em dados secundários. Tais dados compreendem os resultados da avaliação externa do segundo ciclo do Programa Nacional de Melhoria do Acesso e da Qualidade da Atenção Básica (PMAQ-AB), correspondente ao período de 2013 a 2014.

Para o cumprimento da avaliação externa, o Ministério da Saúde desenvolveu uma parceria com Instituições de Ensino Superior (IES), que previamente selecionaram e capacitaram equipes para aplicarem o instrumento de avaliação externa do PMAQ-AB. Para a coleta dos dados as equipes de entrevistadores visitaram in loco as Unidades Básicas de Saúde que aderiram previamente ao PMAQ- $A B$, e levantaram os dados junto às equipes de AB e NASF (Brasil, 2013).

Os pontos que versaram sobre o planejamento e o monitoramento das ações do NASF foram os considerados neste estudo, o que inclui as questões 33.1 a 33.7, 33.11, 33.13, 33.14 e 33.16 do módulo II - referente à entrevista com profissional da equipe de $\mathrm{AB}$ apoiada pelo NASF - e; as questões 7.3 a 7.11, 8.1, 8.2, 9.1 a 9.3, 9.5, 10.1 e 10.2 do módulo IV - referente à entrevista com profissional da equipe de NASF (Brasil, 2013).

Como o Brasil é um país de dimensões continentais, marcado tanto pela diversidade populacional, étnica, histórica e cultural quanto pela desigualdade social e econômica (Kassar, 2012), para análise dos resultados os municípios brasileiros foram divididos de acordo com a classificação preconizada pelo IBGE, em cinco perfis demográficos: 1) Capital: corresponde aos 26 municípios que são capitais de seus estados e o Distrito Federal;2) Região metropolitana: corresponde aos 485 municípios localizados em regiões metropolitanas; 3) G100: corresponde aos 100 municípios com população acima de 80 mil habitantes, com os mais baixos níveis de receita pública per capita e alta vulnerabilidade 
social de seus habitantes; 4) Perfil de pobreza: corresponde aos municípios com 20\% ou mais da população vivendo em extrema pobreza; e 5) Demais localidades: corresponde aos municípios não caracterizados pelos perfis anteriormente citados (Brasil, 2014b).

A partir de tal agrupamento, os dados provenientes da avaliação externa do PMAQ$\mathrm{AB}$ foram tabulados e analisados estatisticamente. A avaliação da associação entre os diferentes perfis de município e as variáveis referentes ao NASF, avaliadas neste estudo, foi realizada por meio do teste do qui-quadrado. Quando a associação foi significativa, a comparação entre os diferentes perfis de município, dois a dois, também foi realizada por meio do teste do qui-quadrado, porém, considerando a correção de Bonferroni nestas comparações, uma vez que foram feitas múltiplas comparações dois a dois, o que aumentaria a chance de erro. Neste caso, a correção de Bonferroni deixa o teste mais rigoroso, sendo que na soma de todos os erros, sua probabilidade não ultrapassasse 0,5 , ou seja, $5 \%$ de erro. A análise estatística foi realizada utilizando o programa estatístico SPSS ${ }^{\circledR}$, versão 22.0, considerando um nível de significância de 5\% (Shott, 1990).

\section{Resultados}

Ao analisar a avaliação externa referente ao NASF no PMAQ-AB em todo o território nacional, obtém-se um total de 18.930 equipes de saúde participantes, sendo estas 17.157 equipes de $\mathrm{AB}$ e 1.773 equipes de NASF. Percebe-se que, dentre os municípios participantes, as capitais apresentam a maior média de equipes de $\mathrm{AB}$ por NASF, seguidas pelo perfil G100, região metropolitana, perfil de demais municípios e de pobreza, respectivamente. A distribuição destas equipes por perfil de município pode ser observada na Tabela 1.

Tabela 1 - Equipes de AB e NASF participantes por perfil de município

\begin{tabular}{|c|c|c|c|c|c|}
\hline & \multicolumn{2}{|c|}{ AB } & \multicolumn{2}{c|}{ NASF } & \multirow{2}{*}{$\begin{array}{c}\text { Média de } \\
\text { AB por } \\
\text { NASF }\end{array}$} \\
\cline { 2 - 5 } & $\%$ & $\mathbf{n}$ & $\%$ & $\mathbf{n}$ & 11,63 \\
\hline Capital & 18,09 & 3104 & 15,1 & 267 & 10,60 \\
\hline G100 & 8,89 & 1526 & 8,1 & 144 & 10,44 \\
\hline $\begin{array}{c}\text { Região } \\
\text { metropolitana }\end{array}$ & 14,24 & 2443 & 13,2 & 234 & 9,51 \\
\hline Demais & 33,7 & 5782 & 34,3 & 608 & 8,27 \\
\hline Pobreza & 25,07 & 4302 & 29,3 & 520 & \\
\hline
\end{tabular}

Fonte: Banco de dados PMAQ-AB $2^{\circ}$ Ciclo, Ministério da Saúde, Brasil (2015).

Como o início da análise corresponde ao processo de implantação do NASF em cada município, apenas as equipes de $\mathrm{AB}$ respondem às primeiras perguntas - sinalizado por "[AB]" antes de cada questão, a partir da próxima tabela, assim como "[NASF]" antecede as questões respondidas pelas equipes de NASF, nas tabelas posteriores. Assim, é possível 
observar que, nacionalmente, a maioria das equipes considera que seria importante outra categoria profissional na composição do NASF.

$\mathrm{Na}$ questão que aborda se o gestor municipal debateu com a equipe de $\mathrm{AB}$ sobre quais categorias profissionais deveriam compor o NASF, foram obtidas respostas positivas em pouco mais da metade dos casos brasileiros. Sobre a composição da equipe de apoio, a categoria fisioterapeuta aparece em primeiro lugar nos perfis de pobreza, G100 e capitais. Já em regiões metropolitanas e demais municípios, esta categoria profissional aparece em terceiro lugar, enquanto que a categoria mais presente nestas equipes de NASF é a de psicólogo.

Ao considerar as três categorias mais encontradas, sem classificá-las ordinalmente, observa-se que o fisioterapeuta, o nutricionista e o psicólogo fazem-se presentes em todos os perfis de município. A categoria médico homeopata apresenta-se como a menos encontrada em equipes de NASF, exceto nas capitais, onde a categoria que menos aparece é a de médico do trabalho, seguida de médico veterinário, médico internista e só então o homeopata, como pode ser observado na Tabela 2 .

Tabela 2 - Implantação do NASF e composição da equipe

\begin{tabular}{|c|c|c|c|c|c|}
\hline Capital & $\begin{array}{c}\text { Região } \\
\text { metropolitana }\end{array}$ & G100 & Pobreza & Demais & Brasil \\
\hline \multicolumn{6}{|c|}{ [AB] Quais profissionais do NASF apoiam sua equipe? } \\
\hline \multicolumn{6}{|c|}{ Fisioterapeuta $(\mathrm{p}<0,001)$} \\
\hline $88,4(2745) b$ & 79,3 (1937)d & $93,1(1420) \mathrm{a}$ & $92,1(3964) \mathrm{a}$ & $85,2(4927) \mathrm{c}$ & $87,4(14993)$ \\
\hline \multicolumn{6}{|c|}{ Psicólogo $(\mathrm{p}<0,001)$} \\
\hline $84,1(2611) \mathrm{c}$ & $90,5(2211) \mathrm{a}$ & $88,5(1350) \mathrm{ab}$ & $85,3(3668) c$ & $88,0(5091) b$ & $87,0(14931)$ \\
\hline \multicolumn{6}{|c|}{ Nutricionista $(\mathrm{p}<0,001)$} \\
\hline $79,5(2469) \mathrm{c}$ & $84,4(2062) b$ & 86,4 (1319)ab & $87,7(3774) \mathrm{a}$ & $85,7(4956) \mathrm{b}$ & $85,0(14580)$ \\
\hline \multicolumn{6}{|c|}{ Assistente social $(\mathrm{p}<0,001)$} \\
\hline $65,1(2022) c$ & $68,1(1664) \mathrm{c}$ & $77,1(1177) \mathrm{a}$ & $71,7(3086) \mathrm{b}$ & $67,5(3901) \mathrm{c}$ & $69,1(11850)$ \\
\hline \multicolumn{6}{|c|}{ Profissional de educação física $(\mathrm{p}<0,001)$} \\
\hline $61,4(1907) \mathrm{b}$ & $62,1(1518) \mathrm{b}$ & $71,4(1089) \mathrm{a}$ & $61,2(2631) b$ & $60,9(3520) \mathrm{b}$ & $62,2(10665)$ \\
\hline \multicolumn{6}{|c|}{ Fonoaudiólogo $(\mathrm{p}<0,001)$} \\
\hline 64,0 (1988)a & $48,9(1194) \mathrm{c}$ & $51,7(789) \mathrm{bc}$ & $52,5(2260) \mathrm{b}$ & $42,9(2482) \mathrm{d}$ & $50,8(8713)$ \\
\hline \multicolumn{6}{|c|}{ Farmacêutico $(p<0,001)$} \\
\hline $50,4(1565) \mathrm{a}$ & $46,5(1137) \mathrm{b}$ & 46,9 (716)ab & $27,6(1188) \mathrm{d}$ & $41,6(2406) c$ & $40,9(7012)$ \\
\hline \multicolumn{6}{|c|}{ Terapeuta Ocupacional $(\mathrm{p}<0,001)$} \\
\hline $47,7(1481) \mathrm{a}$ & $23,2(567) \mathrm{b}$ & $24,4(373) \mathrm{b}$ & $16,9(729) \mathrm{c}$ & $19,0(1098) \mathrm{c}$ & $24,8(4248)$ \\
\hline \multicolumn{6}{|c|}{ Médico pediatra $(\mathrm{p}<0,001)$} \\
\hline $20,5(635) \mathrm{a}$ & $21,8(532) \mathrm{a}$ & $16,1(245) \mathrm{bc}$ & $13,9(598) \mathrm{c}$ & $17,4(1007) \mathrm{b}$ & $17,6(3017)$ \\
\hline \multicolumn{6}{|c|}{ Médico Ginecologista/Obstetra $(\mathrm{p}<0,001)$} \\
\hline $18,1(562) \mathrm{ab}$ & $20,5(500) \mathrm{a}$ & $11,7(178) \mathrm{d}$ & $14,9(643) \mathrm{c}$ & $16,7(967) b c$ & $16,6(2850)$ \\
\hline
\end{tabular}




\begin{tabular}{|c|c|c|c|c|c|}
\hline \multicolumn{6}{|c|}{ Médico psiquiatra $(\mathrm{p}<0,001)$} \\
\hline $29,5(916) \mathrm{a}$ & $19,8(484) \mathrm{b}$ & $13,1(200) c$ & $11,6(497) \mathrm{c}$ & $11,1(644) \mathrm{c}$ & $16,0(2741)$ \\
\hline \multicolumn{6}{|c|}{ Arte Educador (profissional com formação em arte e educação) $(p<0,001)$} \\
\hline $5,8(180) b c$ & $6,8(167) \mathrm{ab}$ & $9,2(140) \mathrm{a}$ & $5,5(237) \mathrm{bc}$ & $5,2(298) c$ & $6,0(1022)$ \\
\hline \multicolumn{6}{|c|}{ Sanitarista $(\mathrm{p}<0,001)$} \\
\hline $5,1(157) \mathrm{a}$ & $3,2(78) b$ & $3,2(49) \mathrm{b}$ & $4,0(173) \mathrm{ab}$ & $3,1(179) \mathrm{b}$ & $3,7(636)$ \\
\hline \multicolumn{6}{|c|}{ Médico Internista (Clínica Médica) $(\mathrm{p}<0,001)$} \\
\hline $2,0(61) \mathrm{c}$ & 4,4 (107)a & $2,9(45) \mathrm{abc}$ & $2,7(116) \mathrm{bc}$ & $3,3(190) a b$ & $3,0(519)$ \\
\hline \multicolumn{6}{|c|}{ Médico Geriatra $(\mathrm{p}<0,001)$} \\
\hline $3,9(122) \mathrm{a}$ & $3,6(88) \mathrm{a}$ & $2,9(44) \mathrm{ab}$ & $1,1(47) \mathrm{c}$ & $2,0(113) \mathrm{b}$ & $2,4(414)$ \\
\hline \multicolumn{6}{|c|}{ Médico Veterinário $(\mathrm{p}<0,001)$} \\
\hline $0,6(20) \mathrm{c}$ & $2,8(69) \mathrm{a}$ & $1,3(20) b c$ & $2,0(87) \mathrm{ab}$ & $2,2(130) a b$ & $1,9(326)$ \\
\hline \multicolumn{6}{|c|}{ Médico Acupunturista $(\mathrm{p}<0,001)$} \\
\hline $2,6(80) \mathrm{a}$ & $1,8(43) \mathrm{abc}$ & $2,2(33) \mathrm{ab}$ & $1,5(66) \mathrm{bc}$ & $1,1(63) \mathrm{c}$ & $1,7(285)$ \\
\hline \multicolumn{6}{|c|}{ Médico do Trabalho $(\mathrm{p}<0,001)$} \\
\hline $0,6(19) \mathrm{c}$ & $2,6(64) \mathrm{a}$ & $1,4(21) \mathrm{abc}$ & $1,1(48) \mathrm{bc}$ & $1,3(77) \mathrm{b}$ & $1,3(229)$ \\
\hline \multicolumn{6}{|c|}{ Médico Homeopata $(\mathrm{p}<0,001)$} \\
\hline $2,5(77) \mathrm{a}$ & $0,7(18) \mathrm{bc}$ & $1,0(16) \mathrm{b}$ & $0,3(12) \mathrm{c}$ & $0,9(51) \mathrm{b}$ & $1,0(174)$ \\
\hline \multicolumn{6}{|c|}{ Outro $(p<0,001)$} \\
\hline $3,5(108) b$ & 6,4 (156)a & $3,3(50) \mathrm{b}$ & 6,0 (260)a & $5,3(308) \mathrm{a}$ & $5,1(882)$ \\
\hline \multicolumn{6}{|c|}{$[\mathrm{AB}]$ Você considera que seria importante outra categoria profissional compor o NASF? $(\mathrm{p}<0,001)$} \\
\hline $86,0(2670) \mathrm{a}$ & $84,7(2068) \mathrm{a}$ & $80,3(1226) b$ & $86,4(3715) \mathrm{a}$ & $85,2(4926) \mathrm{a}$ & $85,1(14605)$ \\
\hline \multicolumn{6}{|c|}{$\begin{array}{l}{[\mathrm{AB}] \mathrm{O} \text { gestor municipal debateu com sua equipe sobre quais categorias }} \\
\text { profissionais deveriam compor o NASF? }(\mathrm{p}<0,001)\end{array}$} \\
\hline \multicolumn{6}{|l|}{$\operatorname{Sim}$} \\
\hline $37,9(1175) \mathrm{e}$ & $55,3(1350) \mathrm{c}$ & $50,1(764) \mathrm{d}$ & $69,0(2968) \mathrm{a}$ & $59,5(3441) \mathrm{b}$ & $56,5(9698)$ \\
\hline \multicolumn{6}{|l|}{ Não } \\
\hline $52,2(1619) \mathrm{a}$ & $36,6(895) b$ & $41,0(626) \mathrm{b}$ & $24,6(1059) \mathrm{d}$ & $32,2(1861) \mathrm{c}$ & $35,3(6060)$ \\
\hline \multicolumn{6}{|l|}{ Não sei } \\
\hline $10,0(310) \mathrm{a}$ & $8,1(198) \mathrm{ab}$ & 8,9 (136)a & $6,4(275) b$ & 8,3 (480)a & 8,2 (1399) \\
\hline
\end{tabular}

Os resultados estão apresentados em frequência relativa (frequência absoluta).Valor de p no teste do qui-quadrado. Letras diferentes na linha indicam diferença significativa entre os diferentes perfis de municípios (teste do qui-quadrado com correção de Bonferroni, $\mathrm{p}<0,05)$, sendo a letra "a" o percentual maior e a letra "e" o percentual menor, ou seja, o perfil de município com a letra "a" apresentou um percentual significativamente maior daquela resposta do que o perfil de município com a letra "b". O perfil de município com a letra "b" apresentou um percentual significativamente maior daquela resposta do que o perfil de município com a letra "c" e assim, sucessivamente.

Fonte: Banco de dados PMAQ-AB $2^{\circ}$ Ciclo, Ministério da Saúde, Brasil (2015).

Quanto aos aspectos que as equipes de $\mathrm{AB}$ consideram reger a atuação do NASF, tanto os dados nacionais quanto de cada perfil de município apontam, em primeiro lugar, a necessidade e/ou demandas da equipe de AB; em segundo lugar, as demandas diretas 
dos usuários; e em terceiro lugar, a realidade epidemiológica e social do território. Sendo que, na entrevista com NASF, as informações fornecidas pela gestão, para reger tal atuação, apresentam opções de resposta não encontradas na questão direcionada às equipes de $A B$, como demonstrado na Tabela 3.

Tabela 3 - Informações de saúde que regem a atuação do NASF, segundo AB e NASF

\begin{tabular}{|c|c|c|c|c|c|}
\hline Capital & $\begin{array}{c}\text { Região } \\
\text { Metropolitana }\end{array}$ & G100 & Pobreza & Demais & Brasil \\
\hline \multicolumn{6}{|c|}{ [AB] Você considera que a atuação do NASF está de acordo com quais aspectos: } \\
\hline \multicolumn{6}{|c|}{ Necessidade/demandas da sua equipe $(\mathrm{p}<0,001)$} \\
\hline $79,7(2474) \mathrm{a}$ & $79,5(1943) \mathrm{a}$ & $74,2(1133) b$ & $79,7(3427) \mathrm{a}$ & $78,5(4537) \mathrm{a}$ & $78,8(13514)$ \\
\hline \multicolumn{6}{|c|}{ Demandas diretas dos usuários $(\mathrm{p}<0,001)$} \\
\hline $62,4(1938) c$ & $65,0(1589) b c$ & $67,4(1029) \mathrm{ab}$ & $69,9(3007) \mathrm{a}$ & $65,6(3793) b$ & $66,2(11356)$ \\
\hline \multicolumn{6}{|c|}{ Realidade epidemiológica e social deste território $(\mathrm{p}<0,001)$} \\
\hline $59,3(1841) b c$ & $60,7(1482) a b$ & $56,0(855) c$ & $62,9(2704) \mathrm{a}$ & $58,5(3383) \mathrm{bc}$ & $59,8(10265)$ \\
\hline \multicolumn{6}{|c|}{ Outros $(p=0,002)$} \\
\hline $15,4(478) \mathrm{a}$ & $15,1(368) \mathrm{a}$ & $13,4(205) \mathrm{ab}$ & $12,6(541) b$ & $13,3(771) \mathrm{ab}$ & $13,8(2363)$ \\
\hline \multicolumn{6}{|c|}{$\begin{array}{l}\text { [NASF] Quais informações de saúde a gestão disponibiliza para sua } \\
\text { equipe para auxiliar no diagnóstico, avaliação e planejamento? }\end{array}$} \\
\hline \multicolumn{6}{|c|}{ Principais demandas das EAB $(p<0,001)$} \\
\hline $77,5(207) \mathrm{ab}$ & $82,1(192) \mathrm{a}$ & $65,3(94) b$ & $82,1(427) \mathrm{a}$ & 81,7 (497)a & $79,9(1417)$ \\
\hline \multicolumn{6}{|c|}{ Principais problemas de saúde do território $(p=0,049)$} \\
\hline $79,0(211) a$ & $81,2(190) \mathrm{a}$ & $68,8(99) \mathrm{a}$ & $79,6(414) a$ & $78,1(475) \mathrm{a}$ & $78,3(1389)$ \\
\hline \multicolumn{6}{|c|}{ Dados epidemiológicos do município $(\mathrm{p}=0,043)$} \\
\hline $71,5(191) \mathrm{ab}$ & $74,4(174) \mathrm{a}$ & $59,7(86) b$ & $70,2(365) \mathrm{ab}$ & $70,9(431) \mathrm{ab}$ & $70,3(1247)$ \\
\hline \multicolumn{6}{|c|}{ Perfil da demanda atendida pelo NASF $(p=0,085)$} \\
\hline $60,7(162) a$ & $59,0(138) \mathrm{a}$ & $55,69(80) \mathrm{a}$ & $66,2(344) \mathrm{a}$ & $64,1(390) \mathrm{a}$ & $62,8(1114)$ \\
\hline \multicolumn{6}{|c|}{ Desafios apontados na autoavaliação $(p=0,201)$} \\
\hline $56,9(152) \mathrm{a}$ & $56,4(132) \mathrm{a}$ & $52,8(76) \mathrm{a}$ & $51,3(267) \mathrm{a}$ & $49,5(301) a$ & $52,3(928)$ \\
\hline \multicolumn{6}{|c|}{ Outras prioridades definidas pela gestão municipal $(\mathrm{p}<0,001)$} \\
\hline $62,5(167) \mathrm{a}$ & $62,4(146) \mathrm{a}$ & $43,1(62) b$ & $49,2(256) b$ & $49,0(298) b$ & $52,4(929)$ \\
\hline \multicolumn{6}{|c|}{ A gestão não disponibiliza informações $(p=0,002)$} \\
\hline $5,2(14) b$ & $6,4(15) b$ & $15,3(22) \mathrm{a}$ & $6,2(32) b$ & $6,6(40) \mathrm{b}$ & $6,9(123)$ \\
\hline
\end{tabular}

Os resultados estão apresentados em frequência relativa (frequência absoluta).Valor de p no teste do qui-quadrado. Letras diferentes na linha indicam diferença significativa entre os diferentes perfis de municípios (teste do qui-quadrado com correção de Bonferroni, $\mathrm{p}<0,05$ ), sendo a letra "a" o percentual maior e a letra "e" o percentual menor, ou seja, o perfil de município com a letra "a" apresentou um percentual significativamente maior daquela resposta do que o perfil de município com a letra "b". O perfil de município com a letra "b" apresentou um percentual significativamente maior daquela resposta do que o perfil de município com a letra "c" e assim, sucessivamente.

Fonte: Banco de dados PMAQ-AB $2^{\circ}$ Ciclo, Ministério da Saúde, Brasil (2015). 
A maioria das equipes de NASF e de AB afirmaram que o planejamento das ações conjuntas foi realizado de forma integrada, conforme exposto naTabela 4, junto aos tópicos discutidos neste planejamento, segundo as equipes de $\mathrm{AB}$, bem como a periodicidade com que as equipes de NASF relatam ocorrer a programação/planejamento de suas ações.

Tabela 4 - Planejamento integrado das ações entre NASF e AB

\begin{tabular}{|c|c|c|c|c|c|}
\hline Capital & $\begin{array}{l}\text { Região } \\
\text { metropolitana }\end{array}$ & G100 & Pobreza & Demais & Brasil \\
\hline \multicolumn{6}{|c|}{$\begin{array}{l}\text { [AB] Quando os profissionais do NASF iniciaram suas atividades de apoio, houve um } \\
\text { momento para articulação/planejamento das ações conjuntas? }(\mathrm{p}<0,001)\end{array}$} \\
\hline $83,4(3425) b$ & $86,9(2500) \mathrm{a}$ & $\begin{array}{l}85,4(4653) \\
\mathrm{ab}\end{array}$ & $83,6(1184) b$ & $85,8(1965) \mathrm{ab}$ & $85,0(13727)$ \\
\hline \multicolumn{6}{|c|}{$\begin{array}{l}\text { [NASF] O planejamento do NASF foi realizado de forma conjunta ou } \\
\text { integrada ao planejamento das equipes } A B ?(p=0,895)\end{array}$} \\
\hline 87,3 (227)a & 87,0 (201)a & 84,7 (122)a & $87,9(430) a$ & 86,7 (504)a & $87,0(1484)$ \\
\hline \multicolumn{6}{|c|}{ [AB] O que foi discutido no planejamento conjunto: } \\
\hline \multicolumn{6}{|c|}{ Pactuação das atividades a serem desenvolvidas $(p<0,001)$} \\
\hline $94,4(2361) \mathrm{a}$ & $90,9(1787) \mathrm{b}$ & $91,7(1086) b$ & $91,6(3139) b$ & $90,7(4219) \mathrm{b}$ & $91,7(12592)$ \\
\hline \multicolumn{6}{|c|}{ Definição de funções e atribuições entre as equipes $(p=0,027)$} \\
\hline $88,5(2212) \mathrm{a}$ & $85,9(1688) \mathrm{a}$ & $86,7(1026) \mathrm{a}$ & $87,6(3001) \mathrm{a}$ & $86,2(4010) \mathrm{a}$ & $87,0(11937)$ \\
\hline \multicolumn{6}{|c|}{ Organização de critérios e fluxos para apoio do NASF $(p<0,001)$} \\
\hline $91,3(2282) \mathrm{a}$ & $86,3(1695) b$ & $87,2(1033) b$ & $86,1(2949) b$ & $85,4(3973) b$ & $86,9(11932)$ \\
\hline \multicolumn{6}{|c|}{ Definição de objetivos, metas e resultados da atuação do NASF $(p=0,012)$} \\
\hline $82,6(2064) \mathrm{ab}$ & $80,0(1572) \mathrm{ab}$ & $81,3(963) \mathrm{ab}$ & $82,9(2839) \mathrm{a}$ & $80,4(3741) b$ & $81,4(11179)$ \\
\hline \multicolumn{6}{|c|}{$\begin{array}{l}\text { Organização de critérios e fluxos para encaminhamento de usuários } \\
\text { a outros serviços/pontos de atenção }(p<0,001)\end{array}$} \\
\hline $84,5(2112) \mathrm{a}$ & $81,9(1609) \mathrm{ab}$ & $82,9(981) \mathrm{a}$ & $78,9(2703) \mathrm{bc}$ & $78,2(3637) \mathrm{c}$ & $80,4(11042)$ \\
\hline \multicolumn{6}{|c|}{ Outros $(\mathrm{p}<0,001)$} \\
\hline $11,2(279) \mathrm{ab}$ & $13,0(256) \mathrm{a}$ & $11,5(136) \mathrm{ab}$ & $12,3(422) \mathrm{a}$ & $9,8(455) \mathrm{b}$ & $11,3(1548)$ \\
\hline \multicolumn{6}{|c|}{ [NASF] A equipe realiza atividade de planejamento e programação de suas ações mensalmente? $(p<0,001)$} \\
\hline $83,5(223) b$ & $91,5(214) \mathrm{ab}$ & $97,2(140) \mathrm{a}$ & $87,9(457) b$ & $86,7(527) b$ & $88,0(1561)$ \\
\hline \multicolumn{6}{|c|}{$\begin{array}{l}\text { [NASF] A equipe realiza atividade de planejamento e programação } \\
\text { de suas ações com qual periodicidade?^ }(\mathrm{p}=0,009)\end{array}$} \\
\hline \multicolumn{6}{|c|}{ Semanal } \\
\hline $38,6(17) \mathrm{a}$ & $40,0(8) \mathrm{a}$ & $50,0(2) \mathrm{a}$ & $20,6(13) \mathrm{a}$ & $22,2(18) \mathrm{a}$ & $27,4(58)$ \\
\hline \multicolumn{6}{|c|}{ Bimestral } \\
\hline $2,3(1) \mathrm{a}$ & $10,0(2) \mathrm{a}$ & $25,0(1) \mathrm{a}$ & $3,2(2) \mathrm{a}$ & $7,4(6) \mathrm{a}$ & $5,7(12)$ \\
\hline \multicolumn{6}{|c|}{ Trimestral } \\
\hline $11,4(5) \mathrm{a}$ & $0,0(0) \mathrm{a}$ & $0,0(0) \mathrm{a}$ & $12,7(8) \mathrm{a}$ & $6,2(5) \mathrm{a}$ & $8,5(18)$ \\
\hline \multicolumn{6}{|c|}{ Semestral } \\
\hline 9,1 (4)a & 20,0 (4)a & 25,0 (1)a & $6,3(4) a$ & $8,6(7) a$ & $9,4(20)$ \\
\hline
\end{tabular}




\begin{tabular}{|c|c|c|c|c|c|}
\hline \multicolumn{7}{|c|}{ Anual } \\
\hline $22,7(10) \mathrm{a}$ & $15,0(3) \mathrm{a}$ & $0,0(0) \mathrm{a}$ & $7,9(5) \mathrm{a}$ & $22,2(18) \mathrm{a}$ & $17,0(36)$ \\
\hline \multicolumn{7}{|c|}{ Não realiza planejamento } \\
\hline $15,9(7) \mathrm{b}$ & $15,0(3) \mathrm{ab}$ & $0,0(0) \mathrm{ab}$ & $49,2(31) \mathrm{a}$ & $33,3(27) \mathrm{ab}$ & $32,1(68)$ \\
\hline
\end{tabular}

Os resultados estão apresentados em frequência relativa (frequência absoluta).Valor de p no teste do qui-quadrado. Letras diferentes na linha indicam diferença significativa entre os diferentes perfis de municípios (teste do qui-quadrado com correção de Bonferroni, $\mathrm{p}<0,05)$, sendo a letra "a" o percentual maior e a letra "e" o percentual menor, ou seja, o perfil de município com a letra "a" apresentou um percentual significativamente maior daquela resposta do que o perfil de município com a letra "b". O perfil de município com a letra "b" apresentou um percentual significativamente maior daquela resposta do que o perfil de município com a letra "c" e assim, sucessivamente.

* Questão aplicada nos casos em que a resposta anterior for negativa, ou seja, a periodicidade não é mensal. Nota: Os dados provenientes da questão 7.6 (“O que foi considerado nesse planejamento?”), da entrevista com profissional do NASF, não foram disponibilizados pelo Ministério da Saúde.

\section{Fonte: Banco de dados PMAQ-AB $2^{\circ}$ Ciclo, Ministério da Saúde, Brasil (2015).}

Entre as equipes de NASF analisadas, pouco mais da metade refere monitorar suas ações direta ou indiretamente. Quando questionado às equipes de NASF se estas realizaram algum processo de autoavaliação nos últimos doze meses, a maioria delas respondeu que sim, como pode ser visualizado na Tabela 5 .

Tabela 5 - Monitoramento e autoavaliação periódica do NASF

\begin{tabular}{|c|c|c|c|c|c|}
\hline Capital & $\begin{array}{l}\text { Região } \\
\text { Metropolitana }\end{array}$ & G100 & Pobreza & Demais & Brasil \\
\hline \multicolumn{6}{|c|}{$\begin{array}{l}\text { [NASF] O NASF participa de monitoramento e análise de indicadores e informações } \\
\text { de saúde em conjunto com as equipes da } \mathrm{AB} \text { apoiadas? }(\mathrm{p}=0,004)\end{array}$} \\
\hline 64,8 (173)ab & 64,5 (151)ab & $59,7(86) \mathrm{ab}$ & $71,3(371) a$ & $61,0(371) b$ & $65,0(1152)$ \\
\hline \multicolumn{6}{|c|}{$\begin{array}{l}\text { [NASF] O NASF realiza monitoramento e análise de indicadores } \\
\text { referentes ao seu processo de trabalho? }(p=0,249)\end{array}$} \\
\hline $75,7(202) \mathrm{a}$ & 71,4 (167)a & $72,9(105) \mathrm{a}$ & $75,4(392) a$ & 70,1 (426)a & $72,9(1292)$ \\
\hline \multicolumn{6}{|c|}{$\begin{array}{l}\text { [NASF] O NASF participa do monitoramento dos Projetos Terapêuticos } \\
\text { Singulares construídos em conjunto com as equipes de } A B ?(p<0,001)\end{array}$} \\
\hline $83,9(224) \mathrm{a}$ & $66,7(156) b$ & $54,9(79) b$ & 56,5 (294)b & $63,7(387) \mathrm{b}$ & $64,3(1140)$ \\
\hline \multicolumn{6}{|c|}{$\begin{array}{l}\text { [NASF] O NASF monitora as solicitações de apoio das equipes, identificando as demandas } \\
\text { mais frequentes e o percentual de atendimento da demanda observada? }(p=0,474)\end{array}$} \\
\hline \multicolumn{6}{|c|}{$\operatorname{Sim}$} \\
\hline 61,4 (164)a & 58,1 (136)a & $55,6(80) a$ & $60,6(315) a$ & $55,6(338) a$ & $58,3(1033)$ \\
\hline \multicolumn{6}{|c|}{ Não } \\
\hline $20,6(55) \mathrm{a}$ & $20,9(49) \mathrm{a}$ & $20,8(30) \mathrm{a}$ & $18,8(98) a$ & $24,3(148) \mathrm{a}$ & $21,4(380)$ \\
\hline \multicolumn{6}{|c|}{ Algumas vezes } \\
\hline $18,0(48) \mathrm{a}$ & $20,9(49) \mathrm{a}$ & $23,6(34) \mathrm{a}$ & $20,6(107) a$ & $20,1(122) a$ & $20,3(360)$ \\
\hline \multicolumn{6}{|c|}{$\begin{array}{l}\text { [NASF] O NASF avalia o impacto/resultado de suas ações nas equipes de } \\
\text { AB apoiadas por meio de quais indicadores/sinalizadores? }\end{array}$} \\
\hline \multicolumn{6}{|c|}{ Análise das situações de saúde dos casos compartilhados $(\mathrm{p}=0,138)$} \\
\hline $68,2(182) \mathrm{a}$ & $67,1(157) \mathrm{a}$ & $64,6(93) \mathrm{a}$ & $61,5(320) \mathrm{a}$ & $60,5(368) a$ & $63,2(1120)$ \\
\hline
\end{tabular}




\begin{tabular}{|c|c|c|c|c|c|}
\hline \multicolumn{6}{|c|}{ Análise dos indicadores de saúde da população do território $(p=0,016)$} \\
\hline $42,7(114) b$ & $47,9(112) \mathrm{ab}$ & $47,2(68) \mathrm{ab}$ & $55,0(286) \mathrm{a}$ & 48,0 (292)ab & $49,2(872)$ \\
\hline \multicolumn{6}{|c|}{ Análise do número de solicitações de atendimentos desnecessariamente direcionadas ao NASF $(p=0,558)$} \\
\hline $46,1(123) \mathrm{a}$ & $42,3(99) \mathrm{a}$ & $47,2(68) \mathrm{a}$ & $47,5(247) \mathrm{a}$ & $43,4(264) \mathrm{a}$ & $45,2(801)$ \\
\hline \multicolumn{6}{|c|}{$\begin{array}{l}\text { Análise do número de encaminhamentos realizados de forma equivocada } \\
\text { ou desnecessária para a atenção especializada }(\mathrm{p}=0,343)\end{array}$} \\
\hline $43,1(115) \mathrm{a}$ & $38,9(91) \mathrm{a}$ & $32,6(47)$ & $40,6(211) \mathrm{a}$ & $39,6(241) \mathrm{a}$ & $39,8(705)$ \\
\hline \multicolumn{6}{|c|}{ Outros $(p=0,641)$} \\
\hline $18,4(49) \mathrm{a}$ & $22,6(53) \mathrm{a}$ & $24,3(35) \mathrm{a}$ & 20,6 (107)a & 21,1 (128)a & $21,0(372)$ \\
\hline \multicolumn{6}{|c|}{ Não avalia o impacto/resultado de suas ações nas equipes apoiadas $(p=0,689)$} \\
\hline $16,5(44) \mathrm{a}$ & $18,8(44) \mathrm{a}$ & $20,1(29) a$ & $19,2(100) \mathrm{a}$ & $20,7(126) \mathrm{a}$ & $19,3(343)$ \\
\hline \multicolumn{6}{|c|}{ [NASF] O NASF realizou algum processo de autoavaliação nos últimos doze meses? $(\mathrm{p}<0,001)$} \\
\hline $95,9(256) \mathrm{a}$ & $90,6(212) \mathrm{ab}$ & 86,1 (124)bc & $79,6(414) c$ & $80,1(487) c$ & $84,2(1493)$ \\
\hline \multicolumn{6}{|c|}{ [NASF] Qual instrumento utilizado? } \\
\hline \multicolumn{6}{|c|}{ AMAQ - NASF $(p=0,190)$} \\
\hline 89,5 (229)a & 90,1 (191)a & $87,9(109) \mathrm{a}$ & $88,9(368) a$ & $93,0(453) \mathrm{a}$ & $90,4(1350)$ \\
\hline \multicolumn{6}{|c|}{ A equipe realizou processo autoavaliativo informal, sem instrumento específico $(p=0,675)$} \\
\hline $9,8(25) \mathrm{a}$ & $9,9(21) a$ & $14,5(18) \mathrm{a}$ & $11,4(47) \mathrm{a}$ & $10,7(52) \mathrm{a}$ & $10,9(163)$ \\
\hline \multicolumn{6}{|c|}{ Instrumento desenvolvido pela própria equipe NASF $(p=0,050)$} \\
\hline $14,8(38) \mathrm{a}$ & $9,4(20) \mathrm{a}$ & 13,7 (17)a & $8,2(34) \mathrm{a}$ & $9,7(47) \mathrm{a}$ & $10,4(156)$ \\
\hline \multicolumn{6}{|c|}{ Instrumento desenvolvido pela Secretaria Municipal de Saúde $(\mathrm{p}<0,001)$} \\
\hline $21,5(55) \mathrm{a}$ & $9,0(19) \mathrm{b}$ & $6,5(8) b$ & $4,1(17) b$ & $4,5(22) \mathrm{a}$ & $8,1(121)$ \\
\hline \multicolumn{6}{|c|}{ Instrumento desenvolvido pela Secretaria Estadual de Saúde $(\mathrm{p}=0,258)$} \\
\hline $0,8(2) \mathrm{a}$ & $2,8(6) \mathrm{a}$ & $1,6(2) \mathrm{a}$ & $1,7(7) \mathrm{a}$ & $0,8(4) \mathrm{a}$ & $1,4(21)$ \\
\hline
\end{tabular}

Os resultados estão apresentados em frequência relativa (frequência absoluta).Valor de p no teste do qui-quadrado. Letras diferentes na linha indicam diferença significativa entre os diferentes perfis de municípios (teste do qui-quadrado com correção de Bonferroni, $p<0,05)$, sendo a letra "a" o percentual maior e a letra "e" o percentual menor, ou seja, o perfil de município com a letra "a" apresentou um percentual significativamente maior daquela resposta do que o perfil de município com a letra "b". O perfil de município com a letra "b" apresentou um percentual significativamente maior daquela resposta do que o perfil de município com a letra "c" e assim, sucessivamente.

Fonte: Banco de dados PMAQ-AB $2^{\circ}$ Ciclo, Ministério da Saúde, Brasil (2015).

Das equipes de $\mathrm{AB}$ participantes, 46,2\% ( $\mathrm{n}=7926)$ consideram a carga horária disponível dos profissionais do NASF à sua equipe "suficiente" ou "muito suficiente", 19,8\% ( $\mathrm{n}=3403)$ considera a carga horária disponível "insuficiente" ou "muito insuficiente" e, as restantes consideram "razoavelmente suficiente", como detalhado na Tabela 6. 
Tabela 6 - Visão das equipes de AB sobre o seu acesso ao NASF

\begin{tabular}{|c|c|c|c|c|c|}
\hline Capital & $\begin{array}{c}\text { Região } \\
\text { metropolitana }\end{array}$ & G100 & Pobreza & Demais & Brasil \\
\hline \multicolumn{6}{|c|}{$[\mathrm{AB}]$ Você considera a carga horária disponível dos profissionais do NASF à sua equipe: $(p<0,001)$} \\
\hline \multicolumn{6}{|c|}{ Suficiente } \\
\hline $21,9(681) \mathrm{d}$ & $39,6(967) \mathrm{c}$ & $35,5(542) \mathrm{c}$ & $51,2(2203) \mathrm{a}$ & $45,1(2610) b$ & $40,8(7003)$ \\
\hline \multicolumn{6}{|c|}{ Razoavelmente suficiente } \\
\hline $38,8(1205) \mathrm{a}$ & $36,3(886) \mathrm{a}$ & $35,8(547) \mathrm{ab}$ & $29,9(1285) \mathrm{c}$ & $32,9(1903) b$ & $34,0(5826)$ \\
\hline \multicolumn{6}{|l|}{ Insuficiente } \\
\hline $31,8(986) \mathrm{a}$ & $17,2(421) \mathrm{b}$ & $19,5(297) b$ & $9,4(404) \mathrm{d}$ & $13,7(790) c$ & $16,9(2898)$ \\
\hline \multicolumn{6}{|c|}{ Muito Suficiente } \\
\hline $1,8(56) \mathrm{c}$ & $4,5(110) \mathrm{b}$ & $4,5(69) \mathrm{b}$ & $8,3(357) \mathrm{a}$ & $5,7(331) \mathrm{b}$ & $5,4(923)$ \\
\hline \multicolumn{6}{|c|}{ Muito Insuficiente } \\
\hline $5,6(175) \mathrm{a}$ & $2,4(59) \mathrm{b}$ & $4,7(71) \mathrm{a}$ & $1,2(53) \mathrm{c}$ & $2,5(147) \mathrm{b}$ & $2,9(505)$ \\
\hline \multicolumn{6}{|c|}{ [AB] Conhece o cronograma/agenda de atividades do NASF com sua equipe? $(\mathrm{p}<0,001)$} \\
\hline $86,6(2688) a$ & $81,8(1999) b$ & $83,2(1269) b$ & $81,6(3510) b$ & $82,8(4790) b$ & $83,1(14256)$ \\
\hline \multicolumn{6}{|c|}{ [AB] Qual a periodicidade dos encontros/atividades dos profissionais do NASF com sua equipe? } \\
\hline \multicolumn{6}{|c|}{ Semanal $(p<0,001)$} \\
\hline $43,4(1347) \mathrm{a}$ & 41,4 (1012)a & $42,5(648) \mathrm{a}$ & $26,7(1148) b$ & $43,5(2518) \mathrm{a}$ & $38,9(6673)$ \\
\hline \multicolumn{6}{|c|}{ Quinzenal $(\mathrm{p}<0,001)$} \\
\hline $13,6(423) \mathrm{c}$ & $17,2(420) a b$ & $20,2(309) \mathrm{a}$ & $18,8(808) \mathrm{a}$ & $15,9(917) \mathrm{bc}$ & $16,8(2877)$ \\
\hline \multicolumn{6}{|c|}{ Mensal $(\mathrm{p}<0,001)$} \\
\hline $32,6(1012) \mathrm{a}$ & $25,7(628) \mathrm{b}$ & $23,1(353) b c$ & $30,6(1316) \mathrm{a}$ & $22,6(1305) \mathrm{c}$ & $26,9(4614)$ \\
\hline \multicolumn{6}{|c|}{ Sem periodicidade definida $(\mathrm{p}<0,001)$} \\
\hline $14,7(455) \mathrm{d}$ & $21,1(516) b c$ & $18,7(286) \mathrm{c}$ & 27,8 (1196)a & $22,5(1300) \mathrm{b}$ & $21,9(3753)$ \\
\hline \multicolumn{6}{|c|}{$\begin{array}{c}\text { [AB] Sua equipe e o NASF criaram critérios em relação aos atendimentos } \\
\text { a serem realizados pelos profissionais do NASF? }(p<0,001)\end{array}$} \\
\hline 82,4 (2497)a & $78,2(1874) \mathrm{b}$ & 74,8 (1115)bc & $74,1(3102) \mathrm{c}$ & $77,6(4367) \mathrm{b}$ & 77,4 (12955) \\
\hline \multicolumn{6}{|c|}{$\begin{array}{l}\text { [AB] Existem critérios e formas definidas e pactuadas entre sua equipe e o } \\
\text { NASF para acionar o apoio em situações imprevistas? }(p<0,001)\end{array}$} \\
\hline 77,0 (2349)a & $72,7(1734) b$ & 71,3 (1060)b & $69,8(2904) b$ & $70,9(3984) b$ & $72,0(12031)$ \\
\hline
\end{tabular}

Os resultados estão apresentados em frequência relativa (frequência absoluta).Valor de p no teste do qui-quadrado. Letras diferentes na linha indicam diferença significativa entre os diferentes perfis de municípios (teste do qui-quadrado com correção de Bonferroni, $\mathrm{p}<0,05$ ), sendo a letra "a" o percentual maior e a letra "e" o percentual menor, ou seja, o perfil de município com a letra "a" apresentou um percentual significativamente maior daquela resposta do que o perfil de município com a letra "b". O perfil de município com a letra "b" apresentou um percentual significativamente maior daquela resposta do que o perfil de município com a letra "c"e assim, sucessivamente.

Fonte: Banco de dados PMAQ-AB $2^{\circ}$ Ciclo, Ministério da Saúde, Brasil (2015).

A maioria das equipes de NASF alegou que o cronograma/agenda de suas atividades foi pactuado com as equipes de $\mathrm{AB}$ apoiadas, que o disponibiliza para as equipes de $\mathrm{AB}$ 
apoiadas e que atuam em horário coincidente com o horário das equipes de $\mathrm{AB}$. Como pode ser conferido na Tabela 7, junto à periodicidade dos encontros do NASF com a AB.

Tabela 7 - Compartilhamento de agenda do NASF com a AB

\begin{tabular}{|c|c|c|c|c|c|}
\hline Capital & $\begin{array}{l}\text { Região } \\
\text { Metropolitana }\end{array}$ & G100 & Pobreza & Demais & Brasil \\
\hline \multicolumn{6}{|c|}{$\begin{array}{l}\text { [NASF] Os profissionais do NASF dedicam um período semanal ou } \\
\text { quinzenal para reunião interna da equipe NASF? }(p=0,001)\end{array}$} \\
\hline $86,9(232) \mathrm{ab}$ & 88,5 (207)ab & $93,8(135) \mathrm{a}$ & $82,7(430) \mathrm{b}$ & $81,4(495) \mathrm{b}$ & $84,5(1499)$ \\
\hline \multicolumn{6}{|c|}{$\begin{array}{l}\text { [NASF] O cronograma/agenda de atividades dos profissionais do } \\
\text { NASF foi pactuado com as equipes apoiadas? }(\mathrm{p}=0,007)\end{array}$} \\
\hline $95,1(254) \mathrm{ab}$ & $92,3(216) \mathrm{ab}$ & $97,2(140) \mathrm{a}$ & $89,6(466) b$ & $93,1(566) \mathrm{ab}$ & $92,6(1642)$ \\
\hline \multicolumn{6}{|c|}{$\begin{array}{l}\text { [NASF] O NASF disponibiliza seu cronograma/agenda de } \\
\text { atividades para as equipes apoiadas? }(p=0,633)\end{array}$} \\
\hline $93,3(249) \mathrm{a}$ & $96,2(225) \mathrm{a}$ & $95,8(138) \mathrm{a}$ & $95,0(494) \mathrm{a}$ & $95,1(578) \mathrm{a}$ & $95,0(1684)$ \\
\hline \multicolumn{6}{|c|}{ [NASF] O NASF atua em horário coincidente com o horário das equipes de $A B / S F ?(p=0,100)$} \\
\hline $100,0(267) \mathrm{a}$ & $99,1(232) a$ & $100,0(144) \mathrm{a}$ & $98,3(511) \mathrm{a}$ & $99,2(603) \mathrm{a}$ & $99,1(1757)$ \\
\hline \multicolumn{6}{|c|}{$\begin{array}{l}\text { [NASF] Com qual periodicidade o NASF realiza atividades/ } \\
\text { encontros com as equipes apoiadas? }(\mathrm{p}<0,001)\end{array}$} \\
\hline \multicolumn{6}{|c|}{ Diariamente } \\
\hline $7,9(21) \mathrm{a}$ & $13,7(32) \mathrm{a}$ & $11,1(16) \mathrm{a}$ & $7,7(40) \mathrm{a}$ & $12,7(77) \mathrm{a}$ & $10,5(186)$ \\
\hline \multicolumn{6}{|c|}{ Semanal } \\
\hline $52,8(141) \mathrm{a}$ & $35,0(82) \mathrm{bc}$ & $41,0(59) \mathrm{ab}$ & $25,6(133) \mathrm{c}$ & $35,5(216) \mathrm{b}$ & $35,6(631)$ \\
\hline \multicolumn{6}{|c|}{ Quinzenal } \\
\hline $5,2(14) \mathrm{a}$ & $7,7(18) \mathrm{a}$ & 7,6 (11)a & $8,7(45) \mathrm{a}$ & $6,4(39) \mathrm{a}$ & $7,2(127)$ \\
\hline \multicolumn{6}{|c|}{ Mensal } \\
\hline $17,6(47) \mathrm{ab}$ & $14,5(34) \mathrm{b}$ & $16,7(24) \mathrm{ab}$ & $23,8(124) \mathrm{a}$ & $18,1(110) \mathrm{ab}$ & $19,1(339)$ \\
\hline \multicolumn{6}{|c|}{ Sem periodicidade definida } \\
\hline $9,4(25) b$ & $12,8(30) \mathrm{ab}$ & $7,6(11) b$ & $18,8(98) \mathrm{a}$ & $13,3(81) \mathrm{ab}$ & $13,8(245)$ \\
\hline \multicolumn{6}{|c|}{ A periodicidade é diferente entre cada uma das equipes apoiadas } \\
\hline $7,1(19) \mathrm{b}$ & $16,2(38) \mathrm{a}$ & $16,0(23) \mathrm{a}$ & $15,4(80) \mathrm{a}$ & $14,0(85) \mathrm{a}$ & $13,8(245)$ \\
\hline
\end{tabular}

Os resultados estão apresentados em frequência relativa (frequência absoluta).Valor de p no teste do qui-quadrado. Letras diferentes na linha indicam diferença significativa entre os diferentes perfis de municípios (teste do qui-quadrado com correção de Bonferroni, $\mathrm{p}<0,05)$, sendo a letra "a" o percentual maior e a letra "e" o percentual menor, ou seja, o perfil de município com a letra "a" apresentou um percentual significativamente maior daquela resposta do que o perfil de município com a letra "b". O perfil de município com a letra "b" apresentou um percentual significativamente maior daquela resposta do que o perfil de município com a letra "c" e assim, sucessivamente.

Fonte: Banco de dados PMAQ-AB $2^{\circ}$ Ciclo, Ministério da Saúde, Brasil (2015). 


\section{Discussão}

Tendo em vista as dificuldades enfrentadas pela saúde pública como um todo e o próprio processo de amadurecimento e efetivação do NASF, o processo de planejamento e monitoramento destas equipes, a partir dos resultados do PMAQ-AB, parece bem organizado em grande parte do país.Já o processo de implantação do NASF nos municípios brasileiros, sobretudo nas capitais, mostra-se bastante falho, como será discutido a seguir.

Como a média de equipes de AB para cada equipe de NASF mostra-se maior nos perfis com maior porte populacional (capital, G100 e região metropolitana, respectivamente), entende-se que estas equipes de NASF apoiam um número mais elevado de equipes de $\mathrm{AB}$ - inclusive que ultrapassa o número máximo de equipes vinculadas, preconizado pelo Ministério de Saúde (Brasil, 2014a).

A maior frequência de equipes de $\mathrm{AB}$ que afirmaram ter participado de debate, com o gestor municipal, a respeito das categorias profissionais que deveriam compor o NASF, pertence ao perfil de pobreza, o que pode representar uma estratégia de melhoria na saúde municipal viável financeiramente. Enquanto que nas capitais a maior parte das respostas foi negativa, com consequente tomada de decisão por parte do gestor municipal, de forma unilateral. Lembrando que, neste processo de implantação, é recomendada a discussão entre gestores, equipe de $\mathrm{AB}$ e população para obter uma avaliação da situação do território e de quais as categorias profissionais mais indicadas para compor a equipe de NASF (Brasil, 2009; Souza; Oliveira; Costa, 2015).

Analisando-se a composição das equipes de NASF, as categorias médicas apresentam nitidamente baixa representatividade no país, dentre as quais o pediatra, o ginecologista/ obstetra e o psiquiatra são os profissionais mais frequentes, enquanto o médico acupunturista, o médico do trabalho e o homeopata são os menos frequentes. Nas capitais, o médico do trabalho é o profissional menos incluído da composição dos NASF, enquanto nos outros municípios o médico homeopata representa a categoria menos frequente, o que sugere que a medicina do trabalho e a homeopatia se enquadram na menor demanda para a $\mathrm{AB}$ dos respectivos municípios e/ou que a oferta destes serviços é escassa nestes locais e/ou que se trata de um recurso humano considerado oneroso.

Já as categorias não médicas de fisioterapeuta, psicólogo, nutricionista, assistente social e profissional de educação fisica apresentam-se como as mais frequentes nas equipes de NASF. Tal dado supõe maior demanda para a $\mathrm{AB}$ nestas áreas do conhecimento - principalmente no cuidado em reabilitação fisica nas capitais, perfil G100 e de pobreza e, em saúde mental nas regiões metropolitanas e demais municípios - e/ou maior oferta de profissionais e/ ou por consistirem em menor custo-beneficio para os municípios, já que o atual piso salarial para profissionais médicos é de $\mathrm{R} \$ 13.847,93$ para 20 horas semanais (Fenam, 2017), enquanto o piso das demais categorias está em torno de 15 a $20 \%$ deste valor para 30 a 44 horas semanais (Fenafito, 2017; FNN, 2016); e algumas delas nem mesmo apresentam piso salarial federal instituído (CFESS, 2017; CFFA, 2011; CFP, 2017; CONFEF, 2017). 
O que contribui para que o NASF não seja médico-centrado e, sim, que se utilize da interdisciplinaridade como ferramenta para atender demandas complexas.

Resultado semelhante foi encontrado no primeiro ciclo do PMAQ-AB (Lima, 2016), no qual os profissionais não médicos (psicólogo, fisioterapeuta, nutricionista, assistente social e farmacêutico) apresentam-se como os mais disponíveis nas equipes de NASF e que as categorias médicas mais encontradas no NASF foram de ginecologista, pediatra e psiquiatra. Percebe-se que entre o primeiro e o segundo ciclo do PMAQ-AB, o fisioterapeuta, o profissional de educação fisica e o pediatra tiveram sua representatividade aumentada nas equipes de NASF em comparação às demais categorias profissionais.

Como a maioria das equipes de $\mathrm{AB}$ referiu ser importante outra categoria profissional compor seu NASF apoiador, pode-se considerar que a atual composição das equipes de NASF não abrange na totalidade as necessidades de apoio na ótica das equipes. Esta expressiva insatisfação pode ter origem na ideia de que a resolutividade depende demasiadamente da categoria profissional e especificidade do saber/formação, "coerente com a fragmentação típica dos “especialismos"” (Souza; Oliveira; Costa, 2015, p. 479).

Embora não se configure como maioria, uma parte das equipes de NASF entrevistadas apontou que não tem acesso a quaisquer informações de saúde que possam auxiliar no diagnóstico, avaliação e planejamento de suas ações, sendo as capitais as menos acometidas por tal falha. Contudo, esta parcela revela-se mais representativa no perfil G100. A referida falta de acesso pode ser uma das razões pela qual as demandas diretas dos usuários aparecem como mais frequentes na regência da atuação do NASF do que a própria realidade epidemiológica e social do território, podendo comprometer o planejar AB-NASF de suas atividades conjuntas e transformar o NASF, erroneamente, em porta de entrada do SUS.

Esse mesmo perfil de município apresentou também a menor frequência de acesso às demandas da AB. O que se revela preocupante, pois este grupo abrange os 100 municípios com população acima de 80 mil habitantes, com os mais baixos níveis de receita pública per capita e alta vulnerabilidade social de seus habitantes. Tais características deveriam ser motivos para que a gestão destes municípios se atentasse ainda mais para as demandas da $\mathrm{AB}$, bem como para o diagnóstico do território, e repassasse tais dados para as equipes de saúde. $\mathrm{O}$ diagnóstico do território e as demandas das equipes de $\mathrm{AB}$ são alicerces para a atuação do NASF - quando se visa qualidade, efetividade, maior alcance e continuidade das ações -, preferencialmente pactuada nas reuniões periódicas com cada uma das equipes de AB apoiadas. Modelo este que auxilia a eficiência e eficácia das ações do NASF, seguindo as recomendações do Ministério da Saúde (Brasil, 2014a; Moura; Luzio, 2014).

No entanto, mesmo que as informações sejam disponibilizadas às equipes, é necessário que exista boa inter-relação e articulação entre NASF e AB para que haja abertura e fluidez em se trabalhar tais demandas. A maioria das equipes entrevistadas, tanto de $\mathrm{AB}$ quanto de NASF, referiu existência de tal articulação e/ou planejamento conjunto das ações interequipes, principalmente nas capitais brasileiras, sendo a pactuação das atividades a serem desenvolvidas e a definição de funções e atribuições entre as equipes os temas mais frequentes 
no referido planejamento. Porém, esses resultados não condizem com os identificados em outros estudos (Barbosa; Ferreira; Furbino, 2010; Barros et al., 2015; Bonaldi; Ribeiro, 2014; Cela; Oliveira, 2015; Farias, 2012; Fernandes et al., 2016; Gonçalves et al., 2015; Lancman; Barros, 2011; Lancman et al., 2013; Leite; Nascimento; Oliveira, 2014; Martinez; Silva; Silva, 2016; Molini-Avejonas et al., 2014), os quais evidenciaram a persistente frustração ao se estudar o trabalho (des)articulado entre as equipes de NASF e AB.

Os perfis "pobreza" e "demais municípios" apresentam as menores frequências em se tratando de organização de critérios e fluxos para encaminhamento de usuários como parte do planejamento. Apesar do PMAQ-AB não especificar tais critérios, acredita-se - levando em conta que, em teoria, o NASF não se caracteriza como porta de entrada e nem como ambulatório de especialidades - que tais critérios estejam relacionados aos tipos de casos a serem encaminhados a outros pontos de atenção ou atendidos pelos profissionais da equipe, como, por exemplo, os usuários acamados e/ou com dificuldade de deambulação, a serem atendidos pelo NASF em visita domiciliar.

Assim, este dado pode ter origem na inexistência ou insuficiência de outros serviços/ pontos de atenção para os quais os usuários possam ser encaminhados, devido à carência de recursos e estrutura desses municípios (Lima, 2016) e/ou na própria organização do trabalho, visto que é diferente da encontrada nas capitais - que pode ser caracterizada como mais sistemática, lembrando que foram encontradas as maiores frequências de criação de critérios em relação aos atendimentos a serem realizados pelos profissionais da equipe de apoio, bem como apresentam a periodicidade mais homogênea com que os NASF realizam atividades/encontros com cada uma das equipes apoiadas.

A definição de periodicidade das atividades do NASF com a AB é determinante na organização da agenda compartilhada, na criação do vínculo com os usuários do território e com a equipe apoiada. E, quanto mais homogênea a periodicidade de encontros com cada equipe de $\mathrm{AB}$, maior é a chance de que nenhuma área seja evitada ou negligenciada, seja devido ao trajeto ser longo e/ou acidentado, à problemática relação interpessoal e/ou interequipes ou qualquer outro motivo. Distribuindo uniformemente o apoio e criando vínculos em todos os territórios.

As atividades de planejamento e programação das ações do NASF são periódicas, e seu não cumprimento conta com poucos casos relatados. A maior parte das equipes declarou realizá-las de modo mensal; a pequena parte restante foi questionada quanto à (outra) periodicidade, tendo como resposta mais frequente que não o realizam principalmente no perfil de pobreza; sem casos relatados no perfil G100 -, seguido do planejamento semanal e do anual, respectivamente.

Apesar da diferença temporal entre as periodicidades mais comuns, o que mais chama a atenção é a frequência de sua não realização pelas equipes atuantes no perfil de pobreza, pois a falta de recursos nestes municípios pode ser fator dificultador na execução das ações em saúde, o que demanda ainda mais planejamento para que aconteçam de fato e com qualidade, sem que seja necessária a utilização de recursos próprios dos profissionais do NASF, exposta por outros estudos (Lancman et al., 2013; Reis;Vieira, 2013). 
Os melhores dados no quesito periodicidade de planejamento foram encontrados no perfil G100, que também se destaca por ser o que mais frequentemente dedica um período semanal ou quinzenal para reunião interna do NASF. O que pode indicar certo mecanismo compensatório empregado pelas equipes de NASF, visto que o perfil G100 é o que menos refere acesso às informações de saúde.

Fica evidente que a menor taxa de contentamento dos profissionais da $A B$, em relação à carga horária disponível dos profissionais do NASF, foi encontrada nas capitais, onde cada NASF é responsável por apoiar uma maior quantidade de equipes de $\mathrm{AB}$ e provavelmente as equipes de NASF organizam-se de maneira diferente. Municípios de grande porte populacional tendem a reservar espaço na agenda para reuniões de equipe com intervalos menores de tempo (Neves; Montenegro; Bittencourt, 2014), mesmo que atendam a grandes demandas. E, como quase a totalidade das equipes de NASF alegou que seu horário de trabalho é coincidente à das equipes de $\mathrm{AB}$, restam duas suposições, descritas a seguir.

A primeira é a de que os NASF podem estar implantados em número insuficiente, principalmente nas capitais, o que limita a frequência do apoio a cada equipe de $\mathrm{AB}$. Essa situação foi observada em Goiânia, onde cada NASF apoiava de 13 a 15 equipes de AB, o que impossibilitava o apoio matricial apropriado (Martinez; Silva; Silva, 2016).

A segunda é a de que a carga horária dos profissionais do NASF é realmente pouco suficiente, nos casos em que a gestão tenha priorizado a variedade de categorias profissionais (com atuação de 20 horas semanais cada) em detrimento da dedicação exclusiva e/ou no caso dos fisioterapeutas e terapeutas ocupacionais, cuja carga horária semanal é de até 30 horas semanais (Brasil, 1994). Paralelamente, as questões financeiras já citadas também podem justificar esses resultados, como ocorre com as especialidades médicas atuantes com reduzida carga horária disponível em comparação às demais categorias profissionais (Fausto et al., 2014; Lima, 2016).

Nessa questão seria interessante que coubesse tanto citar os possíveis motivos da insatisfação, quanto à possibilidade de explicitar se, nesse quesito, a $\mathrm{AB}$ está considerando a carga horária do NASF como um todo ou apenas de determinadas categorias profissionais e, no caso, de quais se apresentam mais deficitárias. Para que, assim, seja possível diagnosticar melhor o problema e, por conseguinte, cogitar estratégias para sua resolução.

Em contrapartida, mostra-se mais comum o monitoramento e análise de indicadores de saúde referentes ao processo de trabalho do NASF realizados de modo isolado, em comparação aos elaborados em conjunto com a $\mathrm{AB}$. Bem como a frequência de monitoramento de Projeto Terapêutico Singular (PTS) construído em conjunto com a $\mathrm{AB}$ também deixa a desejar, com exceção das capitais.

Como esta atuação fragmentada e pontual das equipes de saúde ocorre desde o acompanhamento dos indicadores de saúde até o monitoramento dos PTS, lembrando que se tratam dos dados de um território comum entre tais equipes, o planejamento das ações em saúde para estes locais, famílias e indivíduos não terá a visão integral e 
continuada prevista pelo Ministério da Saúde (Brasil, 2014a; Brasil, 2009) e tão necessária para a implementação de ações resolutivas para o território.

O perfil pobreza apresenta a maior frequência de análise de indicadores de saúde realizada em conjunto com a $\mathrm{AB}$. Tal fato pode acontecer devido a gravidade da situação ser inversamente proporcional aos recursos aos quais tais profissionais têm acesso, o que os leva a perceber que quanto mais completo o quadro de profissionais nas reuniões de monitoramento, mais estratégias viáveis, criativas e resolutivas podem surgir.

Há também o monitoramento do próprio processo de trabalho da equipe de NASF, que corresponde à autoavaliação periódica e cujo principal instrumento citado foi o AMAQ - NASF, em todos os perfis de município. Provavelmente este dado é reflexo do financiamento proveniente do PMAQ, já que o AMAQ faz parte do programa e pode aumentar sua nota final, além de revelar parte dos pontos a serem considerados posteriormente na avaliação externa. É plausível que a autoavaliação periódica não induzida aconteça menos frequentemente por consequência de dois fatores: 1) a cultura centrada no modelo biomédico e insuficientemente autoavaliativa; e 2) a dificuldade em lidar com a sobrecarga de trabalho.

O primeiro se refere à carência de espaço para reflexão e diálogo acerca do processo de trabalho, devido a priorização das metas quantitativas de produtividade (Neves; Montenegro; Bittencourt, 2014), que somada à dificuldade de se implantar uma cultura de autoavaliação satisfatória e constitutiva ao processo de trabalho (Terrasêca, 2016), acaba por manter esta atividade em segundo plano.

Já o segundo tem raiz no desencontro entre a municipalização, o despreparo para tal e a escassez de recursos financeiros (Rizzotto et al., 2014), que pode impedir que sejam implantadas ESF e NASF em quantidade suficiente para atender a demanda do município. E tal deficiência pode, por sua vez, induzir à falta de tempo das equipes para realizar a autoavaliação.

Quanto ao monitoramento das solicitações de apoio, a maioria das equipes de NASF referiu identificar as demandas mais comuns e a frequência de tal atendimento, bem como do impacto/resultado de suas ações (principalmente nos casos compartilhados, seguido dos indicadores de saúde da população do território, do quantitativo de solicitações direcionadas ao NASF desnecessariamente e de encaminhamentos realizados de forma equivocada/desnecessária para a atenção especializada). Mas este índice ainda assim é considerado baixo, devido à sua relevância para o planejamento e processo de trabalho do NASF, bem como para identificação de lacunas da equipe de $\mathrm{AB}$ em relação a demandas recorrentes e/ou que sobrecarreguem o NASF, o que aponta para a necessidade de troca interequipes de saberes/experiências sobre esses temas, proporcionada pelo apoio técnicopedagógico (Gonçalves et al., 2015; Moura; Luzio, 2014).

Assim, caso as equipes de NASF priorizassem o monitoramento das solicitações de apoio das equipes de $\mathrm{AB}$ em seu processo de planejamento periódico, poderiam proceder com estratégias para poupar a própria equipe das demandas repetitivas, como, por exemplo, transferir/devolver demandas de baixa complexidade para os agentes comunitários de 
saúde (ACS), através da educação permanente. E, a partir deste alívio de sobrecarga, dedicar mais tempo e atenção às demais atividades, especialmente as interequipes que fogem ao modelo biomédico, como as discussões de caso entre AB e NASF e a elaboração de PTS.

Considerando as informações disponíveis no portal da atenção básica, o referido ciclo do PMAQ contou com 30.522 equipes de AB e 1.813 equipes de NASF (Brasil, 2015). O que não afeta a representatividade do presente estudo, tendo em vista que grande parte das equipes de $\mathrm{AB}$ participantes não é apoiada por NASF e, portanto, o questionário sobre tal apoio não se aplica a estas equipes de $\mathrm{AB}$.

Em geral, nota-se que o PMAQ constitui um método avaliativo bastante amplo, de abrangência nacional, que contempla questões complementares entre si, principalmente ao se analisar as entrevistas tanto das equipes de $A B$ quanto de NASF, sem o qual não seria possível obter tantas informações sobre estas equipes a nível nacional e, em muitos casos, nem mesmo a nível municipal, visto que monitoramento e autoavaliação - tão importantes para aprimorar o processo de trabalho da equipe e sua resolutividade - não são prioridades das equipes.

Contudo, a discrepância entre os achados da literatura e os resultados do PMAQ-AB trazem algumas reflexões para a cena. Os resultados trazidos por tal avaliação nacional podem não ser totalmente fidedignos, já que, além de depender da memória dos entrevistados, somente são avaliadas as equipes que pactuaram anteriormente com o programa e, sabendo que e quando serão avaliadas, há a oportunidade de preparar um cenário mais "ideal" a partir do que é sabidamente desejável, sobretudo por serem questões perceptivelmente julgadoras do sucesso ou fracasso das equipes, com respostas autorreferidas e ausência de mecanismos que confrontem as informações fornecidas com as realidades das equipes entrevistadas, pois, ainda que esteja previsto no PMAQ-AB a verificação de documentos - como cronograma de atividades e registro de casos compartilhados (Brasil, 2013) -, não há como verificar se estas ações ocorrem de maneira articulada e corresponsabilizada ou apenas em forma de encaminhamento e transferência de responsabilidade. Então, na autoavaliação, as equipes podem mostrar-se mais adaptáveis, resolutivas, organizadas e responsáveis para aumentar sua pontuação e serem financeiramente recompensadas por seu aparente desempenho.

Além destes vieses metodológicos originários do próprio PMAQ, este estudo também apresentou limitação referente à carência de parâmetros comparativos para verificar se, no Brasil e em cada perfil de município, o NASF encontra-se acima ou abaixo das frequências aceitáveis para cada questão. Assim, para se alcançar informações mais confiáveis a respeito da implantação, planejamento e monitoramento do NASF, são necessários estudos que proporcionem a produção de conhecimentos a partir de metodologias complementares, como os de triangulação entre resultados quantitativos e qualitativos, observação participante e não participante, pesquisa interferência, entre outros. 


\section{Conclusão}

Segundo as equipes entrevistadas, a implantação do NASF ocorreu de maneira centralizada na gestão e alheia às demandas da $\mathrm{AB}$, o que, além de ir de encontro ao proposto pelo Ministério da Saúde, também desencadeou insatisfação nas equipes de $\mathrm{AB}$ e, possivelmente, lacunas na assistência ao usuário do SUS. Quanto aos perfis de município, tal falha foi mais branda no perfil de pobreza e mais expressiva nas capitais.

O planejamento de suas ações foi descrito como satisfatório, sobretudo nas capitais brasileiras. Sendo articulado com a AB, principalmente nas regiões metropolitanas. Além de frequente e com boa periodicidade, em especial no perfil G100, no qual, entretanto, as equipes de NASF relataram nem sempre receber as informações necessárias para o planejamento.

Já o monitoramento foi referido como um processo menos comum entre as equipes exceto em se tratando do de PTS nas capitais -, sendo efetivado de forma mais significativa a partir de indução externa, basicamente representada pelo reforço positivo proveniente do PMAQ-AB. Contudo, as equipes participantes deste programa podem também ter descrito uma situação mais favorável à própria equipe do que a real, já que, de modo geral, há tendência de atribuição de pontos positivos para a autoavaliação e negativos para a avaliação de outras equipes e/ou gestão, provavelmente como mecanismo de defesa e/ ou transferência de responsabilidades, por ambicionar elevado conceito final na avaliação e consequente repasse financeiro.

\section{Referências}

BARBOSA, Erika Guerrieri; FERREIRA, Dircilene Leite Santos; FURBINO, Sheila Aparecida Ribeiro. Experiência da Fisioterapia no Núcleo de Apoio à Saúde da Família em Governador Valadares, MG. Fisioterapia em Movimento, v. 23, n. 2, p. 323-330, abr./jun. 2010.

BARROS, Juliana de Oliveira et al. Estratégia do apoio matricial: a experiência de duas equipes do Núcleo de Apoio à Saúde da Família (NASF) da cidade de São Paulo, Brasil. Ciência \& Saúde Coletiva, v. 20, n. 9, p. 28472856,2015 .

BRASIL. Edital n 21, de 31 de março de 2014. Diário Oficial da União, Brasília, DF, 1 abr. 2014b. Seção 3, p. 138.

Lei no 8.856, de 1 de março de 1994. Diário Oficial da União, Brasília, DF, 2 mar. 1994. Seção 1, p. 2957.

. Ministério da Saúde. Secretaria de Atenção à Saúde. Departamento de Atenção Básica. Diretrizes do NASF: Núcleo de Apoio à Saúde da Família. Brasília: Ministério da Saúde, 2009.

Ministério da Saúde. Secretaria de Atenção à Saúde. Departamento de Atenção Básica. PMAQ: manual instrutivo para as equipes de Atenção Básica. Brasília: Ministério da Saúde, 2013.

Ministério da Saúde. Secretaria de Atenção à Saúde. Departamento de Atenção Básica. Núcleo de Apoio à Saúde da Família - Volume 1: ferramentas para a Gestão e para o Trabalho Cotidiano. Brasília: Ministério da Saúde, $2014 \mathrm{a}$

Ministério da Saúde. Secretaria de Atenção à Saúde. Departamento de Atenção Básica. PMAQ transforma realidades (Segundo episódio). Brasília: Ministério da Saúde, 2015. Disponível em: <http://dab.saude.gov.br/ portaldab/pmaq_realidades.php>.Acesso em: 31 jul. 2015. 
BONALDI,Angélica Passos; RIBEIRO, Maressa Daga. Núcleo de Apoio à Saúde da Família: as ações de promoção da saúde no cenário da Estratégia Saúde da Família. Revista de Atenção Primária à Saúde, v. 17, n. 2, p. 195-203, abr./ jun. 2014.

CELA, Mariana; OLIVEIRA, Isabel Fernandes de. O psicólogo no Núcleo de Apoio à saúde da Família: articulação de saberes e ações. Estudos de Psicologia, v. 20, n. 1, p. 31-39, jan./mar. 2015.

CFESS. Perguntas frequentes: Qual é o piso salarial da categoria? E a média de salários? Brasília: Conselho Federal de Serviço Social. Disponível em: <http://www.cfess.org.br/visualizar/menu/local/perguntas-frequentes $>$. Acesso em: 13 jun. 2017.

CFFA. CFFa apresenta principais projetos de lei em tramitação no Congresso Nacional. Brasília: Conselho Federal de Fonoaudiologia, 2011. Disponível em: < http://www.fonoaudiologia.org.br/cffa/index.php/2011/11/cffaapresenta-principais-projetos-de-lei-em-tramitacao-no-congresso-nacional/> . Acesso em: 24 fev. 2017.

CFP. Perguntas frequentes: Há um piso salarial para o psicólogo? Brasília: Conselho Federal de Psicologia. Disponível em: $<$ http://site.cfp.org.br/index.php?cat=perguntas_frequentes\&s $=$ piso\&submit=Buscar $>$. Acesso em: 24 fev. 2017.

CONFEF. Perguntas e Respostas freqüentes sobre o Piso Salarial. Rio de Janeiro. Disponível em: < http://www.confef. org.br/extra/conteudo/default.asp?id=1363>. Acesso em: 24 fev. 2017.

FARIAS, Paula Buttaro. Atuação do nutricionista em equipe multiprofissional na atenção básica de saúde. 2012. 129 f. Dissertação (Mestrado em Saúde Pública) - Faculdade de Saúde Pública da Universidade de São Paulo, São Paulo, 2012.

FAUSTO, Márcia Cristina Rodrigues et al. A posição da Estratégia Saúde da Família na rede de atenção à saúde na perspectiva das equipes e usuários participantes do PMAQ-AB. Saúde em Debate, v. 38, n. especial, p. 13-33, out. 2014.

FENAFITO. Referencia Salarial 2016_2017-FENAFITO. São Paulo: FENAFITO, 2017. Disponível em:<http:// fenafito.com.br/main.asp?link=noticia\&id=28>. Acesso em: 24 fev. 2017.

FENAM. Piso e Consulta FENAM têm novo valor para 2017. Brasília: Imprensa FENAM, 2017. Disponível em: <http://www.fenam.org.br/noticia/6314>. Acesso em: 24 fev. 2017.

FNN. Tabela de honorários nutricionistas - 2016. Florianópolis: Federação Nacional dos Nutricionistas, 2016. <Disponível em: http://fnn.org.br/admin/conteudos/arquivos/tabela_2016.pdf>. Acesso em: 24 fev. 2017.

FERNANDES, Janainny Magalhães et al. NASF's tools and practices in health of physical therapists. Fisioterapia em Movimento, v. 29, n. 4, p. 741-750, out./dez. 2016.

GONÇALVES, Rita Maria de Abreu et al. Estudo do trabalho em Núcleos de Apoio à Saúde da Família (NASF), São Paulo, Brasil. Revista Brasileira de Saúde Ocupacional, v. 40, n.131, p. 59-74, 2015.

KASSAR, Mônica Carvalho Magalhães. Educação especial no Brasil: desigualdades e desafios no reconhecimento da diversidade. Educação \& Sociedade, v. 33, n. 120, p. 833-849, jul./set. 2012.

LANCMAN, Selma;BARROS, Juliana Oliveira. Estratégia de saúde da família (ESF), Núcleo de Apoio à Saúde da Família (NASF) e terapia ocupacional: problematizando as interfaces. Revista de Terapia Ocupacional da Universidade de São Paulo, v. 22, n. 3, p. 263-269, set./dez. 2011.

LANCMAN, Selma et al. Estudo do trabalho e do trabalhar no Núcleo de Apoio à Saúde da Família. Revista de Saúde Pública, v. 47, n. 5, p. 968-975, 2013.

LEITE, Denise Fernandes; NASCIMENTO, Débora Dupas Gonçalves do; OLIVEIRA, Maria Amélia de Campos. Qualidade de vida no trabalho de profissionais do NASF no município de São Paulo. Physis - Revista de Saúde Coletiva, v. 24, n. 2, p. 507-525, 2014.

LIMA, Juliana Gagno. Atributos da Atenção Primária nas regiões de saúde: uma análise dos dados do Programa Nacional de Melhoria do Acesso e da Qualidade da Atenção Básica. 2016. 244 f. Dissertação (Mestrado em Saúde Pública) - Escola Nacional de Saúde Pública Sergio Arouca, Rio de Janeiro, 2016. 
MARTINEZ, Jéssica Félix Nicácio; SILVA, Maria Sebastiana; SILVA, Ana Márcia. O Núcleo de Apoio à Saúde da Família em Goiânia (GO): percepções dos profissionais e gestores. Saúde em Debate, v. 40, n. 110, p. 95-106, jul./ set. 2016.

MELO, Lygia Maria de Figueiredo et al. Análises das diretrizes para o apoio institucional das gestões da Atenção Básica das capitais brasileiras. Saúde em Debate, v. 40, n. 108, p. 8-22, jan./mar. 2016.

MOLINI-AVEJONAS, Daniela Regina et al. Inserção e atuação da Fonoaudiologia nos Núcleos de Apoio à Saúde da Família. CoDAS, v. 26, n. 2, p. 148-154, 2014.

MOTA, Roberta Rodrigues de Alencar;DAVID, Helena Maria Scherlowski Leal. Programa Nacional de Melhoria do Acesso e da Qualidade da Atenção Básica: questões a problematizar. Revista de enfermagem UERJ, v. 23, n. 1, p. 122-127, jan./fev. 2015.

MOURA, Renata Heller de; LUZIO, Cristina Amélia. O apoio institucional como uma das faces da função apoio no Núcleo de Apoio à Saúde da Família (NASF): para além das diretrizes. Interface - Comunicação, Saúde, Educação, v. 18, Supl. 1, p. 957-970, 2014.

NASCIMENTO, Cynthia Maria Barboza do B. Núcleo de Apoio à Saúde da Família: uma análise da atenção à saúde em municípios da região metropolitana do Recife. 2014. 182 f. Tese (Doutorado em Saúde Pública) - Centro de Pesquisas Aggeu Magalhães, Fundação Oswaldo Cruz, Recife, 2014.

NEVES, Teresa Cristina de Carvalho Lima; MONTENEGRO, Luiz Albérico Araújo; BITTENCOURT, Sonia Duarte de Azevedo. Produção e registro de informações em saúde no Brasil: panorama descritivo através do PMAQ-AB. Saúde em Debate, v. 38, n. 103, p. 756-770, out./dez. 2014.

REIS, Fernanda;VIEIRA, Ana Cléa Veras Camurça. Perspectivas dos terapeutas ocupacionais sobre sua inserção nos Núcleos de Apoio à Saúde da Família (NASF) de Fortaleza, CE. Cadernos de Terapia Ocupacional da UFSCar, v. 21, n. 2, p. 351-360, 2013.

RIZZOTTO, Maria Lucia Frizon et al. Força de trabalho e gestão do trabalho em saúde - revelações da Avaliação Externa do PMAQ da AB no Paraná. Saúde em Debate, v. 38, n. especial, p. 237-251, out. 2014.

SHOTT, Susan. Statistics for health professionals. London:W.B. Saunders Company, 1990.

SOUZA, Diogo de; OLIVEIRA Isabel Fernandes de; COSTA, Ana Ludmila Freire. Entre o especialismo e o apoio: psicólogos no Núcleo de Apoio à Saúde da Família. Psicologia USP, v. 26, n. 3, p. 474-483, 2015.

TERRASÊCA, Manuela. Autoavaliação, avaliação externa... Afinal para que Serve a Avaliação das Escolas? Cadernos Cedes, v. 36, n. 99, p. 155-174, maio/ago. 2016. 


\title{
Deployment, planning and monitoring of Family Health Support Centre: a national study based on PMAQ
}

\begin{abstract}
The study analyzes NASF implantation, planning and monitoring. It is based on external assessment of the second cycle of PMAQ-AB data, grouped according to the counties profile types classification proposed by IBGE, and the sample consists by 18.930 health teams. The support team composition was unsatisfactory to $\mathrm{AB}$, however the articulated action planning was frequent, especially metropolitan areas. Most teams evaluate themselves only through the program self-evaluation. NASF was implanted without proper articulation with AB, managercentralized, especially in capitals, where, however, planned its actions more systematically. This planning was organized, periodic and articulated, but using compensatory mechanisms by NASF in profiles characterized by socioeconomic vulnerability. The monitoring still is an underexplored activity in the whole country, except when induced by the financial incentive proportional to the program participating teams score.
\end{abstract}

Key words: Primary health care, family health strategy, patient care team, employee performance appraisal, remuneration.

\section{Implantación, planificación y monitoreo del Núcleo de Apoyo a la Salud de la Familia: un estudio nacional a partir del PMAQ-AB}

\section{Resumen}

El estudio analiza la implantación, planificación y monitoreo del NASF. Se fundamenta en los datos de la evaluación externa del segundo ciclo del PMAQ-AB, agrupados según la clasificación de los perfiles de municipio propuesta por el IBGE, siendo la muestra compuesta por 18.930 equipos de salud. La composición de los equipos de apoyo se presentó insatisfactoria para la $\mathrm{AB}$, pero la planificación conjunta de las acciones se mostró frecuente, principalmente en regiones metropolitanas. La mayoría de los equipos revelaron que se evaluaron sólo a través de la autoevaluación del programa. El NASF fue implantado sin la debida articulación con la $\mathrm{AB}$, centralizada en la gestión, principalmente en las capitales, donde, sin embargo, planificó sus acciones de forma más sistemática. Tal planificación se mostró organizada, periódica y articulada, pero con mecanismos compensatorios por parte de los NASF en los perfiles caracterizados por la vulnerabilidad socioeconómica. El monitoreo sigue siendo una actividad subexplotada en todo el país, excepto cuando son inducidas por el incentivo financiero proporcional a la nota de los equipos participantes del programa.

Palabras clave: Atención primaria de salud, estrategia de salud familiar, grupo de atención al paciente, evaluación del rendimiento de empleados, remuneración. 